\title{
Os sistemas bibliográficos em Gabriel Peignot: uma metabibliografia científica
}

\section{Gustavo Silva Saldanha}

\author{
Doutor em Ciência da Informação pelo Programa \\ de Pós-Graduação em Ciência da Informação \\ IBICT - UFRJ. Pesquisador Adjunto - IBICT. \\ Professor Adjunto - Unirio.
}

Leyde Klebia Rodrigues da Silva

Doutoranda em Ciência da Informação pelo Programa de Pós-Graduação em Ciência da Informação IBICT - UFRJ.

http://dx.doi.org/10.1590/1981-5344/3234

A reflexão epistemológico-histórica estabelece uma relação entre o pensamento de Gabriel Peignot, o repertório de sistemas bibliográficos mapeado pelo bibliógrafo em sua obra Dictionnaire Raisonné de Bibliologie e os potenciais analítico-discursivos que emergem a partir das cartografias de ciências e saberes anteriores ao século XIX. Como estudo teóricoexploratório, busca-se identificar as influências de Peignot (como Bacon, Diderot, D'Alembert e Condillac) e dos sistemas por ele abarcados, conduzindo-nos à elaboração e à repercussão histórica de classificações bibliográficas. As conclusões apontam para um conjunto de abordagens que permitem o reconhecimento de fontes para a história da ciência e para uma cartografia epistemológica distinta em uma historiografia das classificações, bem como das próprias vertentes epistemológicas e suas institucionalizações que antecederam o Oitocentos.

Palavras-chave: Gabriel Peignot. Sistema bibliográfico. Classificação bibliográfica. Modernidade. História da Ciência. 


\section{Gabriel Peignot's bibliographic systems: a scientific metabibliography}

The epistemological-historical reflection establishes a relation between Gabriel Peignot's thought, the repertoire of bibliographic systems mapped by the bibliographer in his work Dictionnaire Raisonné de Bibliologie, and the analytic-discursive potentials that emerge from the cartographies of sciences before the 19th century. As a theoretical-exploratory study, the aim was to identify the influences of Peignot (such as Bacon, Diderot, D'Alembert and Condillac) and the systems covered by it, leading to the elaboration and historical repercussion of bibliographic classifications. The conclusions pointed to a set of approaches that allow the recognition of sources for the history of science and for a distinct epistemological cartography for a historiography of the classifications, as well as of the epistemological aspects themselves and their institutionalizations that preceded the nineteenth century.

Keywords: Gabriel Peignot. Bibliographic System. Bibliographic Classification. Modernity. History of Science.

Recebido em 31.05.2017 Aceito em 30.06.2017

\section{Introdução à "sistemática" de Peignot}

Sistema significa em geral uma reunião ou encadeamento de princípios e conclusões, ou bem ainda o todo e o conjunto de uma teoria cujas diferentes partes estão ligadas entre si, seguem-se umas às outras e dependem umas das outras. (DIDEROT, D'ALEMBERT, 2015, [1751], p. 402-403)

Como nos explica o verbete anônimo da Enciclopédia (DIDEROT, D'ALEMBERT, 2015, [1751], p. 403), a palavra "sistema" responde por uma transliteração do grego que significa composição ou reunião. Aproximada da "bibliografia", na expressão "sistemas bibliográficos", a noção ganha uma condição conceitual de relevância histórica central para a fundamentação dos estudos informacionais. Trata-se simultaneamente de um processo, de um método, de uma abordagem e de um instrumento (uma "tecnologia") de observação e de construção do "real empírico". Essa reflexão segue os rastros da manifestação de tal conceito na 
alvorada do século XIX em Gabriel Peignot (1802a, b). Fruto do desenvolvimento de uma reflexão epistemológico-histórica, bem como de uma discussão sobre o papel da linguagem na fundamentação do campo informacional, a reflexão aqui tecida procura descortinar conceitos e discuti-los à luz de uma leitura crítica sobre a contemporaneidade da Ciência da Informação (CI) projetada a partir de seu passado.

Dois projetos convergentes integram a reflexão, "Trilhar o trivium: a filosofia da Ciência da Informação na tradição filosófica da linguagem" e "Epistemologia histórica do pensamento biblioteconômico-informacional: a trama da linguagem entre instituições, conceitos, artefatos e intersujeitos". O resultado de tal convergência levou à construção de uma terceira frente, o projeto que "sobressai" a partir do encontro das perspectivas atrás, intitulado "Ciência da Informação, Filosofia da Linguagem e Filosofia da Cultura: da epistemologia histórica informacional ao pensamento linguístico-simbólico nos estudos informacionais". A proposta aqui está na relação entre uma epistemologia histórica e a filosofia da linguagem como elementos que permitem perceber o papel do simbólico na fundamentação informacional contemporânea.

A partir das inquietações de tais estudos, a reflexão epistemológicohistórica presente no trabalho estabelece uma relação entre o pensamento de Gabriel Peignot, o repertório de sistemas bibliográficos mapeado pelo bibliógrafo em sua obra Dictionnaire Raisonné de Bibliologie (chamado aqui DRB) e os potenciais analítico-discursivos que emergem a partir das cartografias de ciências e saberes anteriores ao século XIX. Especificamente, busca-se aqui o reconhecimento e a descrição dos chamados "sistemas bibliográficos" cartografados por Gabriel Peignot até o ano de 1802.

Como estudo exploratório, busca-se identificar a elaboração e a repercussão histórica de classificações bibliográficas, as características centrais do reportório peignotiano. Desdobra-se, pois, uma discussão sobre o papel de tais sistemas nos séculos anteriores à sua consolidação, e seus modos de repercussão, sugeridos pela profusão de formas e de conteúdos expressos no repertório disponível no DRB.

As conclusões apontam para um conjunto de abordagens que permitem o reconhecimento de fontes para a história da ciência e para uma cartografia epistemológica distinta para uma historiografia das classificações, bem como das próprias vertentes epistemológicas e suas institucionalizações que antecederam o Oitocentos. Integra-se ainda ao debate a fundamentação de uma "metabibliografia científica", ou seja, a capacidade de revelar saberes a partir de uma preocupação em repertoriar e em posicionar cada sistema existente.

\section{0 percurso metodológico: a geoconceitualidade e suas dinâmicas de movimentação no solo epistemológico}

O estudo dos jogos de linguagem é o estudo das formas primitivas da linguagem ou de linguagens primitivas. (...) Quando examinamos essas formas simples de linguagem, a névoa mental que parece 
encobrir o uso habitual da linguagem desaparece. (WITTGENSTEIN, 1992, p. 47)

O território empírico desta reflexão é fruto da construção de um percurso de "garimpo conceitual": trata-se, com o presente estudo, da feitura de uma tetralogia (que pode ser chamada de "tetralogia peignotiana", a qual esperamos ainda aberta), sobre o Dictionnaire raisonné de bibliologie, publicado em 1802, que procura reconhecer a construção epistêmica do que trata como Bibliologia, uma vasta ciência estruturada na linguagem, orientada para a compreensão dos complexos modos de circulação do pensamento a partir dos registros manifestados em livros e toda a miríade de materialidades sígnicas. Influência direta de Paul Otlet (1934) para o desenvolvimento da Bibliologia do advogado belga, ou suas Ciências Bibliológicas, ou, ainda, a Documentologia, a obra e seus conceitos são fundamentais para a compreensão de distintas elaborações teóricas e metodológicas do que hoje tratamos como Ciência da Informação.

O itinerário metodológico tecido para a tetralogia percorre uma vivência epistemológica de fundo wittgensteiniano, orientada para a compreensão de um jogo de conceitos tecido no "solo áspero" das relações sociais de uma dada comunidade de uso da linguagem. Trata-se da busca dentro e na forma de vida de um grupo daquilo que Wittgenstein (1979) chama de "linguagem primitiva" - não confundível com arcaísmos ou qualquer ideia de linguagem que aponte para o passado categórico. Ao contrário, trata-se da produção do conhecimento que se encontra ali, diante dos olhos, ontem ou hoje, o modo pragmático através do qual um certo conjunto de sujeitos consegue se comunicar. Procura-se, pois, uma espécie de "geoconceitualidade" - os conceitos em seu território de uso e suas movimentações.

No percurso, "conceitos disciplinares", "conceitos teoréticos" e "conceitos ferramentais" são, pois, identificados, dentro do que já identificamos como uma discussão "geoconceitual", atenta ao aparecimento, sedimentação, sobreposição, "descoberta", reavaliação, reapropriação e outros movimentos de manipulação de conceitos para a efetivação de discursos epistêmicos. No vocabulário foucaultiano (FOUCAULT, 2010), trata-se de um processo arqueológico de compreensão das formações discursivas, seus enunciados, e suas demarcações simultaneamente materiais e não visíveis.

O que tratamos por "conceitos disciplinares" indica a representação de formas de vida da linguagem, segundo o léxico wittgensteiniano, que apontam para macro-noções solidificadas como responsáveis por um vasto território epistêmico (não necessariamente a "razão epistemológicocientífica", ou a prática empírica refletida como "ciência" na Modernidade, mas o conjunto de saberes representados por um "pan-conceito"). Como exemplo, encontramos as noções de Bibliografia e Bibliologia, "responsáveis" por abarcar complexos científicos na visão de diferentes epistemólogos. 
O que abordamos como "conceitos teoréticos" responde pela identificação de "noções fortes", carregadas de uma pragmática consolidada em seu espaço-tempo, dentro de uma dada episteme, que estabelece a possibilidade de comensurabilidade dentro de uma forma de vida. É o caso, por exemplo, das noções de "controle bibliográfico universal" ou "bibliometria". Representam conceitos que se estabelecem dentro de um campo ou em suas fronteiras, reunindo sob a sombra de seu significante (e suas variações) abordagens, métodos, técnicas e outros conceitos.

Por fim, identificamos os "conceitos-ferramentais", extremamente comuns nas ciências sociais aplicadas. No plano específico do campo informacional, a partir da reflexão epistemológico-histórica de Viviane Couzinet (2012, 2011, 2009a, 2009b, 2008, 2004) reconhecemos duas modalidades fronteiriças, porém distintas, deste conjunto de demarcações conceituais, ou seja, os "conceitos-artefatos" e os "artefatos conceituais". No primeiro caso, tomando por base uma hermenêutica do modo couzinetiano de "fazer história" da Documentação, no contexto francês, trata-se de observar as ideias-coisas, ou a hibridação de documentos. Trata-se de abordar o "documento" como um conceito espectral, ou seja, um complexo de conceitos que, em sua unidade, representa a "unidade múltipla" de um conceito em sua abertura à interpretação.

Por sua vez, em um segundo caso, identificamos no gesto historiográfico de Couzinet (2012, 2011, 2009a, 2009b, 2008, 2004) o que reconhecemos como "artefatos conceituais", ou um conjunto de "coisas-conceito", ou ainda o potencial de identificação das hibridações da organização do conhecimento. Em linhas objetivas, trata-se de perceber os instrumentos metalinguísticos e metamateriais tecidos no campo informacional, como bibliografias, vocabulários controlados, tesauros, como artefatos "puramente" conceituais, ou produzidos com uma teleologia metaconceitual.

É no cenário das "coisas-conceito" ou dos "artefatos conceituais" que identificamos a sistemática peignotiana cartografada dentro do DRB. Trata-se de "dar à vista" um conjunto de hibridações conceituais tanto de "conceitos disciplinares" quanto de "conceitos teoréticos" que apontam para uma "linguagem primitiva" do campo hoje reconhecido como Ciência da Informação. Os "sistemas bibliográficos" em Peignot (1802b) são, pois, aqui tratados como "artefatos conceituais" passíveis de revelar elementos centrais da Modernidade em seu nascimento e consolidação. Por sua vez, tais construtos demarcam, como veremos, a "guerra dos enunciados", a concretude das disputas pela demarcação dos discursos científicos no alvorecer da Modernidade. Eis um plano crítico que pode ser tratado, com Bourdieu (2004), como uma economia política da epistemologia visualizada através dos e, ao mesmo tempo, criada pelos sistemas bibliográficos. 


\section{Achegas aos "sistemas peignotianos": a "Modernidade sistematizada" e a posição peignotiana}

O conhecimento natural, puro e imaculado pelo qual Adão atribuiu nomes apropriados para as coisas não está relacionado com a oportunidade ou ocasião da Queda. O método e o modo da tentação, de fato, foi o desejo ambicioso e exigente por conhecimento moral, pelo qual pudesse discriminar o bem do mal, com o objetivo de o homem poder afastar-se de Deus e fazer suas próprias leis. (BACON, 2014 [1620], p. 25)

Gabriel Peignot está dentro do contexto de "consolidação" de uma relação de co-constituição entre registro e Modernidade. Trata-se de um modo de tomar a noção de fixação no mundo material como parte integrante de uma racionalidade sustentada pelo mundo sensível. Na mesma ambientação socioepistêmica, encontramos a aproximação objetiva entre Modernidade e Ciência (empírica). Trata-se de uma teoria do conhecimento sustentada pela condição do método demonstrativo a partir do escopo das materialidades.

Nesse sentido, a "sistemática" de Peignot, apresentada no início do século XIX, representa objetivamente um ponto de vista que esquematiza o real-empírico dos séculos anteriores, uma espécie de espelho da Modernidade-maquínica: trata-se de compreender como sua compilação de sistemas colabora não apenas para afirmar uma historicidade epistêmica em plena transformação desde o Renascimento Cultural principalmente, desde o século XIII. Como lembra o verbete anônimo da Enciclopédia, "O cartesianismo, que sucedeu a escola peripatética, tornou moda o gosto pelos sistemas". (DIDEROT, D'ALEMBERT, 2015, [1751], p. 403) Peignot e "seus" sistemas demarcam um ponto de vista central para a afirmação da história da ciência - mas, agora, uma história da episteme empírica, com ênfase cada vez maior no mecanicismo.

Ainda no plano da contextualização do sujeito e seu espaço-tempo, Peignot integra um debate central sobre a "questão sistêmica" do próprio modelo distinto de prática científica que se coloca naquele momento. Nossa observação chama a atenção sobre o modo como, para além de uma forma de perceber a construção da ciência moderna e constituir subsídios para pensá-la, historicizá-la e atestá-la, Peignot se integra objetivamente ao próprio modelo epistêmico de seu mundo.

A reunião de sistemas e sua preocupação em descrever cada um coloca o sujeito em "sintonia" com todo o debate sobre o próprio conceito de "sistema", sendo também, a obra peignotiana, um modelo de reflexão sobre a singularidade do sistema na Modernidade, o aparecimento de uma sociedade dos sistemas, que vai da discussão sobre os antigos sistemas filosóficos à multiplicação de sistemas naquela contemporaneidade orientados para repertoriar as novas cientificidades em luta por emancipação. Trata-se, pois, de um pensamento diretamente influenciado 
por um contexto epistêmico que é profundamente marcado por sistemas como O Novo Organon e a Encyclopédie.

Publicado no início do século XVII, o Novo Organon de Francis Bacon declara a relação de contiguidade entre um mundo epistêmico e um mundo mecânico: pensamento e máquina se aproximam, na medida em que o processo mental pode ser replicado nas estruturas da esfera do sensível. A chamada "grande renovação" postulada por Bacon (2014) em sua obra, nada menos que propõe a procura de novos e mais dinâmicos meios para uma renovação geral das ciências. $O$ foco está nas demonstrações e experiências ainda pouco divulgadas e, principalmente, a miríade de possibilidades de desenvolvimento de tais processos que estão por vir. Técnica, especialização e experimento se entrecruzam na nova sistemática.

O tecido do universo, sua estrutura, para a mente que o observa, é como um labirinto, onde o caminho para qualquer lado é muitas vezes incerto, a imagem de uma coisa ou um sinal é enganoso e as voltas e reviravoltas da natureza são bastante oblíquas e intricadas. É preciso sempre viajar através das florestas dos experimentos e das coisas particulares, sob a luz incerta dos sentidos, que brilha por vezes e se esconde em outros momentos. (BACON, 2014, p. 23)

O desenvolvimento da ciência está, pois, em uma relação de uso, pensamento, observação e argumento, relacionando diretamente o pensar e o aplicar. Ou, nas palavras de Bacon (2014, [1620], p. 25), a busca pelo "casamento eterno, verdadeiro e legítimo entre as faculdades empíricas e as racionais", "cujo triste e infeliz divórcio e separação têm causado muitos problemas para a família humana". Para tal, um processo necessário, exigido por essa nova "instauração", ou novos modos de "interpretação da natureza", é justamente a meta que servirá, posteriormente, para Gabriel Peignot cartografar com suas bibliografias o mundo das sistemáticas classificatórias: repensar as divisões das ciências, reclassificá-las. Trata-se de verificar o conjunto de ciências (existentes e por vias de se constituir) de fundo indutivo, capazes de observar a natureza assim como ela se apresenta.

As ciências precisam de uma forma de indução que faça experimentos e os analise, chegando a conclusões necessárias com base em exclusões e rejeições apropriadas. E, ao notar que a forma usual de julgamento dos lógicos tem sido árdua e tem requerido muito esforço intelectual, resta saber quanto mais esforço deveríamos despender com esse outro julgamento, que é projetado não apenas a partir das profundezas da mente, mas também das entranhas da natureza. (2014, [1620], p. 30).

A apresentação de Peignot (1802b, p. 256) do verbete referente ao sistema da Enciclopédia demarca claramente o ponto de partida que toma as influências de Bacon, Diderot e D'Alembert como centralidades para o novo pensamento científico e, logo, para uma nova classificação das 
ciências, a necessidade de identificar, nomear e ordenar o conjunto de inovações empíricas que eram elaboradas entre os séculos XVII e XVIII. $\mathrm{Na}$ posição do discurso peignotiano, antes de Bacon as ciências podiam ser consideradas nulas.

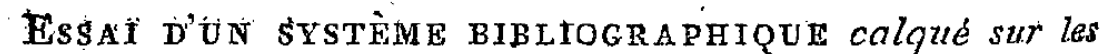
trois grandes divisions áto lEncyclopédie, et précédé d'une notice sur l'ótlté observé par Bacon, d'Alembert et Diderot, dons le tableati sommaire des connaissances huntaines.

Avất Bacon, les sciences étaient, pour ainsi dire, nulles; la scholastique faisait d'Aristote un impitoyable tyran, tout en défigurătit sés immortelles productions; on se servait des bornés que l'irexpérience de son siècle avaient mises à son génie pour comprimer celıi des modernes qui voulaient les fratichir. La religion èt les lois ne rougirent point dé prêtê quelqua fois seconars a l'aveugle routine qui défen-

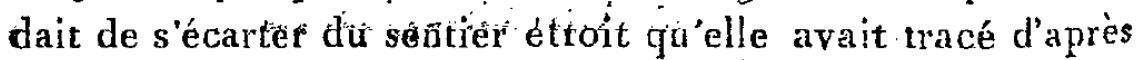
les principes les plus abstraits et les plus intelligibles du

Figura 1. Fragmento inicial do verbete Système Bibliographique de I'Encyclopédie

Fonte: Peignot (1802b)

Um século depois essas visões estão devidamente demarcadas: a viagem às "entranhas da natureza" é marca central do conjunto de verbetes do "livro das Luzes". Na Enciclopédia, é clara a posição de destaque do papel do conceito de "sistema" para o discurso filosófico do Iluminismo. No verbete sem autoria pré-estabelecida, a noção de sistema é compreendida como uma disposição de diferentes partes de uma ciência ou de uma arte, constituintes em um dado espaço onde tais partes se sustentam mutuamente e dentro do qual umas explicam as outras. (DIDEROT, D'ALEMBERT, 2015, [1751]). Esse foi o conceito objetivamente apropriado por Gabriel Peignot para o reconhecimento dos sistemas bibliográficos.

Nesse sentido,

As [partes] que dão a razão de outras se chamam princípios, e o sistema é mais perfeito quanto menor o número de princípios; é desejável mesmo que se reduza a um único. Pois, assim como num relógio, há um mecanismo principal, do qual todos os outros dependem; há, também, em todos os sistemas, um princípio primeiro a que estão subordinadas as diferentes partes que 0 compõem. (DIDEROT, D’ALEMBERT, 2015, [1751], p. 400)

Como na ilustração do sistema da "relojoaria", o complexo de construção do conhecimento integra a relação de movimento, dentro do mundo sensível, de partes que permitem ao próprio sistema existir 
enquanto tal. O sistema, é, pois, a co-constituição de partes que, por sua vez, só existem em sua co-existência dinâmica no todo.

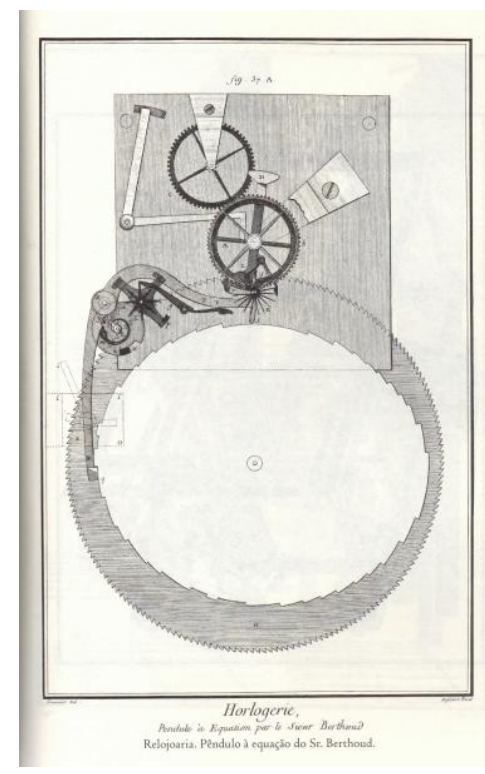

Figura 2. "Relojoaria"

Fonte: (DIDEROT, D'ALEMBERT, 2015, [1751], p. 414)

$\mathrm{Na}$ "historicidade" do "sistema", a Enciclopédia apresenta três espécies de princípios, a partir dos quais são desdobradas, por sua vez, três espécies de sistemas. Primeiramente, encontram-se as máximas gerais ou abstratas. A metafísica seria a principal corrente fundadora e utilizadora de tal espécie sistêmica. Em segundo lugar, encontram-se as chamadas suposições (hipóteses), construídas para estabelecer um modo de explicação que não poderia ser dado de outra forma através da razão. Reúnem-se aqui as condições de determinação de princípios da natureza. Sua constituição está vinculada à crítica aos sistemas abstratos oriundos da metafísica, incapazes de estabelecer uma explicação plausível para determinados elementos do mundo físico. Por final, encontram-se os fatos propriamente ditos, elementos resultantes daquilo que a experimentação recolheu, consultou e averiguou. (DIDEROT, D'ALEMBERT, 2015, [1751])

$\mathrm{Na}$ visão apresentada na Enciclopédia, encontramos aqui o ponto de vista científico moderno. "Por conseguinte, chamarei de sistemas abstratos os que dependem de máximas abstratas, de hipóteses os que têm por funcionamento meras suposições e de verdadeiros sistemas os que se apoiam unicamente em fatos comprovados" (DIDEROT, D'ALEMBERT, 2015, [1751], p. 400). O discurso da Enciclopédia, recorre, pois, à revisão de Étienne Condillac (1715-1780), filósofo das Luzes, consequentemente crítico da metafísica. Em suas obras, sobressai um olhar objetivo sobre o mundo sensível - o "sensualismo" como o léxico filosófico nos demonstrará. Condillac é autor das obras "Ensaio sobre a origem dos conhecimentos humanos", de 1746, "Tratado dos Sistemas", de 1749, e "Tratado das Sensações", de 1754. 
O "sensualismo" e a noção de "sistema" em Condillac influenciarão profundamente a construção de uma epistemologia atípica para os milênios anteriores. Trata-se de uma preocupação política de transformação epistemológica, ao lado de uma preocupação epistemológica de revolução política, assim como a Enciclopédia propunha em seus verbetes. Dentre as repercussões da obra condillaciana, está a elaboração do pensamento químico em Lavoisier (CARVALHO, 2012).

Lavoisier inspirou-se em Condillac: linguagem e conhecimento são indissociáveis e, por isso, refazer a linguagem é refazer a ciência. A Lógica de Condillac foi publicada em 1780 e fornecia os argumentos teóricos necessários à justificação das mudanças defendidas por Lavoisier. A nova nomenclatura proposta por Lavoisier e seus colaboradores tinha um conteúdo "ideológico", pois quem a aceitasse estaria consequentemente aceitando a teoria do oxigênio, unificadora dos fenômenos de oxidação, combustão, respiração e acidez. A nova nomenclatura foi apresentada em quatro sessões públicas na Academia Real de Ciências, entre abril e junho de 1787, sob a forma de memórias, que comporiam a obra Método de nomenclatura química (Méthode de nomenclature chimique) (cf. Guyton de Morveau et al., 1787). (CARVALHO, 2012, p. 762)

Trata-se de uma maneira de perceber o mundo a partir de um método empírico que responde por um método classificatório (nomear integra a capacidade do espírito em compreender a natureza). A linguagem e seu potencial organizador e discriminatório, o âmbito arbitrário e as margens experimentais que existem em sua condição, são fundamentais não apenas para o conhecimento das ciências, mas também para a criação e o desenvolvimento das mesmas. Constitui-se, pois, em Condillac, um método linguístico-analítico próprio.

Somente pela análise deve ser feita a instrução, e a condução deve ser feita do conhecido para o desconhecido. Desde que as línguas tornaram-se métodos analíticos, pensamos segundo os hábitos que provêm delas. As línguas das ciências possuem os mesmos defeitos que as outras, "mas as ciências fizeram progressos, porque os filósofos observaram melhor e colocaram em sua linguagem a precisão e a exatidão que haviam colocado em suas observações" (Condillac, 1973 [1780], p. 117). A análise só nos ensinará a raciocinar na medida em que nos ensinar a determinar as ideias abstratas e gerais e a fazer bem a nossa língua. A arte de raciocinar só se reduz a uma língua bem feita porque a organização das nossas ideias está subordinada aos nomes dos gêneros e espécies. A simplicidade das expressões facilita o raciocínio e a análise utiliza uma língua mais simples. (CARVALHO, 2012, p. 766, grifo nosso)

A analítica sistemática da linguagem fundamenta, pois, o método de conhecer e de criar as ciências e suas ferramentas. O processo não está deslocado, por sua vez, de um processo classificatório. A ciência é, antes 
(durante e depois), o ato de, linguisticamente, compor o científico, produzir novas línguas, fazê-las comensuráveis. A classificação das ciências, de seus ramos, a nova árvore do conhecimento, é uma ciência da linguagem, como bem veria Peignot (1802a,b), na medida em que é, fundamentalmente, uma ciência que espelha a Modernidade.

\begin{abstract}
Enfim, as línguas são métodos analíticos, o raciocínio só se aperfeiçoa se as línguas se aperfeiçoarem, e a arte de raciocinar, cujo exercício depende do uso das palavras, só pode ser exercida através de uma língua bem feita que contenha os meios que permitam as análises. A álgebra é um método analítico e é uma língua, prova decisiva de que os progressos das ciências dependem dos progressos das línguas. A nova nomenclatura química foi entendida como uma ofensiva contra o flogisto e desencadeou uma forte controvérsia. A linguagem da academia diferia, em grande parte, da linguagem utilizada pelos artesãos e pelos droguistas. Além disso, os artesãos farmacêuticos viam na nova nomenclatura uma manobra com o objetivo de criar uma dependência dos artesãos com respeito aos acadêmicos (cf. Abrantes, 2006). (CARVALHO, 2012, p. 766, grifo nosso)
\end{abstract}

A "língua-analítica" de Condillac representa, pois, a infraestrutura, a estrutura e a aplicação de um sistema. Este nada mais é do que o arranjo dos diferentes elementos de uma arte ou de uma ciência numa ordem que os torna mutuamente dependentes, um reflexo do classificar. Os elementos primários levam e explicam os últimos. Aqueles que explicam os outros são chamados princípios, e o sistema é tanto mais perfeito quanto os princípios são menos numerosos: é até desejável que sejam reduzidos a um. Em todos os sistemas existe um primeiro princípio ao qual os diferentes elementos que os compõem estão subordinados. (CONDILLAC, 1991)

O abade de Condillac (1991), em seu tratado dos sistemas de 1749, aplicou-se particularmente à descrição de todos os sistemas abstratos. Segundo ele, existem três tipos de princípios abstratos em uso. Os primeiros são proposições gerais exatamente verdadeiras em todos os casos. O segundo são proposições verdadeiras nos modos mais marcantes. E por isso somos levados a supor que são verdadeiros em todos os aspectos. Os últimos são alguns relacionamentos vagos que nós imaginamos entre coisas de uma natureza diferente. O primeiro não conduz a nenhum lugar. Os outros dois só levam a erros. E isso é o que o autor do tratado sobre sistemas prova pelo exame de diferentes sistemas.

Dessa maneira, não existe uma ciência ou uma arte em que os sistemas não possam ser feitos. Mas, em alguns, se propõem a explicar os efeitos. Enquanto em outros, para organizar e causá-los. (CONDILLAC, 1991). A tarefa de Peignot $(1802 a, b)$, acreditamos, é procurar a compreensão de tais ciências a partir da própria constituição do método analítico da linguagem. 


\section{0 labirinto dos sistemas: a cartografia de Peignot}

Jusqu'à ce moment, on ne connait pas aucun système bibliographique parfait, e peut-être est-il impossible d'atteindre à cette perfection désirée. (PEIGNOT, 1802b, p. 200)

Um dos mais extensos e detalhados verbetes do DRB, os systèmes bibliographiques ocupam, desde à introdução à obra, uma posição privilegiada no repertório peignotiano. Ao todo, identificamos formalmente na descrição de Peignot (1802b) o total de 23 sistemas, caracterizados conforme suas especificidades. Dentre estes, selecionamos, de modo aleatório, uma amostra sintética que ilustra a complexidade da sistemática reunida na obra peignotiana.

O intuito, não sendo exaustivo, procura, em tal aleatoriedade, identificar elementos que permitem comprovar os elementos de uma geoconceitualidade e uma sistemática que demonstram a relevância epistemológico-histórica da obra e das ideias de Peignot (1802a, b). A ausência de dados completos, como datação, origem e, por vezes, autor do sistema, é adotada, no trabalho, a partir das fontes diretas da listagem peignotiana. O próprio Peignot (1802a) esclarece, na introdução do DRB, que se trata de um conjunto abreviado de sistemas e seus principais fundadores.

SYSTYMF BIBLIOGRAPHIQUE. On nomme ains Jardre obseryé dans une classification quelconque d'oü -rrages, soit imprimés, soit manuscrits, pour former une biblifthèque un catalogue de liyres. Jusqu'à ce moment

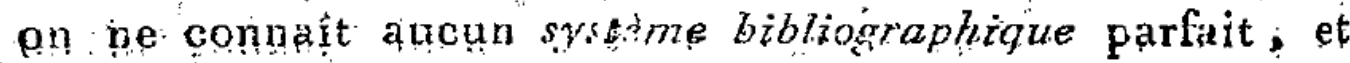
peut être est-il-jupossible d'atteindre à cette perfection désirée, car \& co systère dif un ąuteur judicieux, consisto disce cl sous oniser en diverses closses tout ce quifait l'objet ce nos connaissances, chacune des classes primitives poùant étre considénée comme un trong qui porte des branches, des rameaux et des feuilles; et la diffultéa surmonter pour établir entre toutes ces parties lordre gat leur conyent, est ${ }^{\circ}$ de fixer le rang que les classes pris mitives deivent teup entre elles o de rapporter a chacuno

Figura 3. Fragmento inicial do verbete Système Bibliographique em Gabriel Peignot

Fonte: Peignot (1802b) 
A primeira questão relevante coloca em ênfase a unidade do conceito de "sistema bibliográfico". Essa marca terminológica demonstra, a nosso ver, a relação direta de influência de pensamentos como de Bacon, Diderot, D'Alembert e Condillac em Peignot (1802a, b). O bibliólogo francês reconhece a "imperfeição" dos sistemas bibliográficos existentes - "on ne connait pas aucun système bibliographique parfait" (PEIGNOT, 1802b, p. 200) e a impossibilidade de atingir a totalidade de representação do universo do conhecimento.

Logo na introdução ao verbete "sistemas bibliográficos" Peignot apresenta o método completo de criação de tais instrumentos, a saber,

[...] consiste à diviser et sous-diviser en diverses classes tout ce qui fait l'objet de nos connaissances, chacune des classes primitives pouvant être considérée comme un tronc qui porte des branches, des rameaux et des feuilles; et la difficulté à surmonter pour établir entre toutes ces parties l'ordre qui leur convient, est, $1^{0}$ de fixer le rang que les classes primitives deivent tenir entre elles; 20 de rapporter à chacune d'elles la quantité immense de branches, de rameaux et de feuilles qui lui appartiennent. (PEIGNOT, 1802b, p. 200-201)

Peignot (1802b) destaca alguns trabalhos que "seguiram" tal método, como Gabriel Naudé, em 1627, em Avis pour dresser une bibliothèque e Louis-Jacob de Saint-Charles, Traité des plus belles bibliothèques publiques et particulières. Outra ênfase, ainda na introdução ao verbete, está na importância, para o século XVII, de um dos sistemas mais recomendados para exposição e organização dos livros, aquele do Colégio de Clermont elaborado pelos Jesuítas de Paris (Systema bibliothecae collegii parisiensis societatis Jesu, 1678). Tal sistema isolava as classes teologia, filosofia, história e direito.

Como mencionado, para essa reflexão um grupo específico e aleatório de descrições peignotianas foi pré-definido como amostra de sua cartografia. Dentre os sistemas selecionados, apresentamos aqui:

Système du citoyen Ameilhon

Système de'Arias Montanus

Système de Baillet

Système de la bibliothèque nationale de Paris

Système du citoyen Butenschoen

Système bibliographique de l'abbé Girard

Système de Laire

O Système du citoyen Ameilhon, segundo Peignot (1802b), destacase a partir da posição das classes de Literatura e Belas Artes, afastando a noção de Teologia como "classe-cabeça" do catálogo. Ameilhon propôs, 
nesse sentido, a mudança pela Gramática (livros destinados ao estudo das línguas), em seguida a ciência que se destinaria ao entendimento, Lógica, seguida pela Moral e depois a Jurisprudência, seguida pela Metafísica (que compreendia títulos de seres imateriais, Deus e o espírito, na qual se encaixaria a Teologia). Artes se manteria intacta, exceto "Belas-Letras" que passaria para classe de Gramática. E com relação à classe de História, as mudanças seriam: ao invés de História Civil vir depois da História Eclesiástica, seria História Universal, Civil e Profana, História Eclesiástica Universal e História Civil ou Profana de cada nação, e, a História Eclesiástica particular de cada país.

O système de'Arias Montanus respondia pela publicação, em latim, de 1635, de descrições com foco para a Biblioteca de Escurial. Ele apresentava em seu trabalho o sistema de ordenação adotado por Arias Montanus. O presente sistema dividia primeiro as obras por língua, em seguida separava os impressos dos manuscritos, e, depois, distribuía o livros de cada língua em 64 classes, a saber: grammatica, vocabularia, elegantioe, fabuloe, poesis, historia, antiquaris, dialectica, rhetorica, declamatio, orationes, epistoloe, ars memorioe, mathematica in genere, geometria, arithmetica, musica, cosmographia, geographia, topographia, astrologia, astronomia, divinatio, perspectiva, principes philosophi, naturalis filosofia, philosophi privati argumenti, chymica, metaphysica, oeconomica, politica, aulica, civile, jus, juris civilis interpretes, gironomicoe proeceptiones, id est, seniorum documenta; mecânica, venatio, aucupium, piscatio, colymbilica (urinalrix), militaris, architectura, idyilia opuscula, stromata, encyclica, catholica, biblia et patres, concordantioe índices, oeconomioe loci communes, bibliorum commentaria, canones, concilia, constitutiones religiosae, canonicum jus, doctores integri, homiliae, orationes, epistoloe, soliloquia, hymni, doctrinales, et semidispulatorii, apologioe, disputationes privatoe et defensores, privata quoedam et revelationes, historia ecclesiastica et vitoe sanctorum, scholastica theologia, summistoe, etc.). (PEIGNOT, 1802b)

O Système de Baillet foi apresentado na obra Jugement des Savans, de 1722. O sistema adotava uma classificação dividida em 6 partes: $1^{0}$ Os imprimeurs (pessoas que exerciam a arte de imprimir) destacados pelo seu saber, sua indústria, sua precisão e confiabilidade, são eles: os critiques (dominam o conhecimento contido nos livros), os critiques grammairiens (filólogos e pessoas das "belas-letras"), os grammairiens (artistas ou técnicos das letras) e os traducteurs (tradutores, principalmente do Latim e línguas vulgares); 20 Os poètes e todos os encarregados das obras de ficção: poètes prosaïques (autores de romance, ficção e prosa), rhéteurs (os oradores responsáveis pelos discursos), orateurs (os escritores das peças de eloquência), épistolaires (autores de cartas); 30 historiens (historiadores) aqueles responsáveis pela descrição/relato dos lugares, do tempo e da ação dos homens: os chronologistes (historiadores do tempo), os historiens (historiadores de pessoas), as histoires spéciales (hitórias dos lugares, países e pessoas particulares), os antiquaires (aqueles que tratam de diversos usos das 
humanidades, em todos os tipos de tempo e lugares, de forma filológica, isto é, a história literária para explicar religião, ritos, costumes e os modos de viver dos povos); 40 Os philosophes também chamados por Baillet de naturalistes, médecins e mathématiciens, ou seja, os autores que trataram das artes liberais em geral; $5^{\circ}$ Os acteurs do direito que conduzem e estabelecem as regras e condutas entre os homens (direito civil, eclesiástico, os escritores da política e da moral e os economistas); $6^{\circ}$ Os théologiens (teólogos) que escrevem sobre religião e teologia: os théologiens de positive (que trabalham com as sagradas escrituras), os Pères (que trabalham a teologia ministerial) $\mathrm{e}$, os théologiens scholastiques (teólogos escolásticos). Segundo Peignot (1802b), esse sistema foi usado para o catálogo da Bibliothèque de Lamoignon.

Um dos sistemas mais explorados por Peignot (1802b), claramente pela sua proximidade e pela vastidão do conteúdo que se distribuía sob sua estrutura, foi o sistema da Biblioteca Nacional de Paris. O sistema era composto por 5 grandes classes: a théologie, a jurisprudence, a histoire, a philosophie e as belles-lettres.

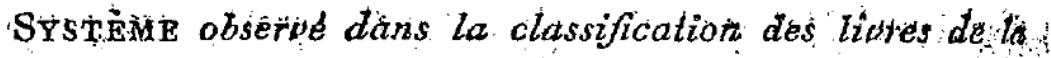

bibliotheque nationale, a paris. Nous allons pariler dé

l'ordre établi dans cette bibliothèque avant la révolution

françaisé; nous ne croyons pas qu'il ait été changé depuis.

Cette magnifique collection est divisée en cinqu grandes

classes, savoir : la théologie, 3 la jurisprtıdence, l'histoire,

la phillosopluie et les belles-lettrës. Ces cinq classes exigeant

de nouvelles divisions et des subdivisions telles que la nature

des livres les présente, pour ainsi dire, à l'esprit, on les

2 divisées en vingt-trois parties; à cliacune desquelles on

a assigné une lettre de l'alphabet ( $I$ ), et à chaque lettre des numéros relatifs à ceux que les livres portent dans les

tablettes. La théologie est comprise sous les lettres $A_{\text {, }} B$, $\mathrm{C}, \mathrm{D}$; la jurispritudence, sous $\mathbf{E}, \mathrm{F}$; lihistotre; sous $\mathrm{G}$; $\mathbf{H}, \mathrm{J}, \mathrm{K}, \mathrm{L}, \mathrm{M} ; \mathrm{N}, \dot{\mathrm{O}}, \mathrm{P}, \mathrm{Q} ;$ la philosophie, sous $\mathbf{R}, \mathrm{S}, \mathrm{T}, \mathrm{V}$; et les belles-lettres, sous $\mathbf{X}, \mathbf{Y} ; \mathrm{Z} . \mathrm{Passon}$ u détail sommaire.

Figura 4. Fragmento inicial do verbete Système de la bibliothèque nationale em Gabriel Peignot

Fonte: Peignot (1802b)

Essas classes eram divididas e subdividas em novas classes de acordo com o conteúdo dos livros existentes na biblioteca. Cada uma delas era dividida em vinte e três partes e algumas eram destacadas com letras do alfabeto. Para cada letra, números eram relacionados às prateleiras dos livros. Quanto aos manuscritos desta biblioteca, eles eram divididos por fundos, e recebiam o nome daqueles por quem foram vendidos ou doados ao rei. O Quadro 1 representa a estrutura do sistema.

\begin{tabular}{|c|c|cc}
\hline Classe & Letras & Divisão
\end{tabular}




\begin{tabular}{|c|c|c|}
\hline \multirow{4}{*}{ TEOLOGIA } & $\mathrm{A}$ & Sagrada escritura, interpretes judeus e cristãos e críticas sagradas \\
\hline & $\mathrm{B}$ & $\begin{array}{l}\text { As liturgias e os concílios, tantos os gerais como nação quanto os sínodos provinciais e } \\
\text { diocesanos }\end{array}$ \\
\hline & $\mathrm{C}$ & Os pais da igreja (fontes de conhecimento do cristianismo) gregas e latinas \\
\hline & $\mathrm{D}$ & $\begin{array}{c}\text { Os teólogos das igrejas gregas e romanas } \\
\text { Os teólogos heterodoxos e os autores de erros particulares }\end{array}$ \\
\hline \multirow[t]{2}{*}{ JURISPRUDÊNCIA } & $\mathrm{E}$ & $\begin{array}{c}\text { Direito canônico } \\
\text { Direito da natureza e das pessoas }\end{array}$ \\
\hline & $\mathrm{F}$ & Direito civil \\
\hline \multirow{10}{*}{ HISTÓRIA } & $\mathrm{G}$ & Geografia, cronologia, história universal, história antiga e história geral. \\
\hline & $\mathrm{H}$ & $\begin{array}{c}\begin{array}{c}\text { Eclesiástica (antigo e novo testamento), Da ordem religiosa e militar e das heresias e } \\
\text { inquisições }\end{array} \\
\end{array}$ \\
\hline & $\mathrm{J}$ & História antiga (gregos, bizantinos, turcos e romanos) \\
\hline & $\mathrm{K}$ & História da Itália, Roma moderna, dos diferentes estados da Itália e ilhas adjacentes. \\
\hline & $\mathrm{L}$ & História da França e suas províncias \\
\hline & $\mathrm{M}$ & $\begin{array}{c}\text { História da Alemanha e dos impérios de países da Europa oriental, países do norte e da } \\
\text { Holanda }\end{array}$ \\
\hline & $\mathrm{N}$ & História dos três reinos: Inglaterra, Escócia e Irlanda \\
\hline & $\mathrm{O}$ & $\begin{array}{c}\text { História da Espanha e Portugal e de países para além da Europa e das viagens a Ásia, } \\
\text { África e Américas. }\end{array}$ \\
\hline & $\mathrm{P}$ & Histórias hibridas - personalidades ilustres (homens e mulheres) das artes e da ciência \\
\hline & $\mathrm{Q}$ & Histórias literárias, jornais e bibliografias \\
\hline \multirow{4}{*}{ FILOSOFIA } & $\mathrm{R}$ & Filosofia antiga (grega e latina), moderna, tratados de lógica, metafísica, moral e física \\
\hline & $\mathrm{S}$ & História natural e geral, em particular dos animais, vegetais e minerais \\
\hline & $\mathrm{T}$ & $\begin{array}{l}\text { Medicina antiga (árabe e latina), medicina moderna organizada por nação, e, os } \\
\text { anatomistas e cirurgiões, os químicos e alquimistas }\end{array}$ \\
\hline & $\mathrm{V}$ & A Matemática e suas diferentes partes \\
\hline \multirow{3}{*}{ BELAS-LETRAS } & $\mathrm{X}$ & Gramáticos e oradores \\
\hline & $\mathrm{Y}$ & $\begin{array}{c}\text { Romances, contos e novelas } \\
\text { Mitologia, poetas, fabulistas organizados por país e ordem cronológica }\end{array}$ \\
\hline & $\mathrm{Z}$ & $\begin{array}{l}\text { Filólogos, Epistolares e Polígrafos } \\
\text { Comércio, algumas artes dependentes da literatura }\end{array}$ \\
\hline
\end{tabular}

Quadro 1 - Representação do sistema bibliográfico da "Bibliothèque nationale" de Paris

Fonte: Peignot (1802b, p. 208-210)

O système du citoyen Butenschoen (professor de história da HautRhin em Calmar), representa, de acordo com Peignot (1802b), um método enciclopédico. Butenschoen acreditava, ao contrário de Ameilhon, que a divisão enciclopédica era mais simples e mais "natural" e que poderia ser adotada para a organização de uma grande biblioteca.

SYSTËME diza citoyen Butenschoent, professeutr drtistoire dı Hart-Rhin, à Calmar. Cet estimable prófesseur, trèsversé dans la littérature du Nord, et dans la bibibliographie générale et particulière, remplizi les fonctions de bibliothéçaire dans le Haut-Rbin. Le systéme qua if a eu la complaisance de me communiquer, est encyclopédicine. Lauteur croit, contre l'opinion du savant Ameilhon, que lá division encyclopédique est la plus simple et la plus naturelfe que l'on puisse adopter dans l'arrangement d'itne grande bibliothéque (r). Mais co dans le monde littéraire eómme dans le monde moral et politique, dit tauteur, il y arura toujours des individus difficiles à ranger dans les classes ordimaizes, et rien nemp êche de former une classe particulière,

Figura 5. Fragmento inicial do verbete Système du citoyen Butenschoen em Gabriel Peignot 
Fonte: Peignot (1802b)

O sistema possuía dez grandes divisões, cada divisão com seções e as seções subdividas em parágrafos, com cadeias inferiores conforme a especialização dos assuntos. O quadro a seguir detalha como esse sistema estava estruturado:

\begin{tabular}{|c|c|}
\hline \multicolumn{2}{|c|}{ Système du citoyen Butenschoen } \\
\hline Classes/Categorias principais & Seções/Parágrafos... \\
\hline $\begin{array}{l}\text { INTRODUÇÃO GERAL ÀS CIÊNCIAS, LETRAS E ARTES } \\
\text { (primeira classe) }\end{array}$ & $\begin{array}{l}\text { 1. Origem do conhecimento humano } \\
\text { 2. Objetos do conhecimento humano } \\
\text { 3. Erudição. Vantagens e desvantagens das letras, ciências e } \\
\text { artes } \\
\text { 4. Metodologia universal. } \\
\text { 5. Meios de comunicar, propagar e conservar o conhecimento } \\
\text { 6. } \text { Variadas }\end{array}$ \\
\hline $\begin{array}{l}\text { LITERATURA E BELAS-ARTES } \\
\text { (segunda classe) }\end{array}$ & 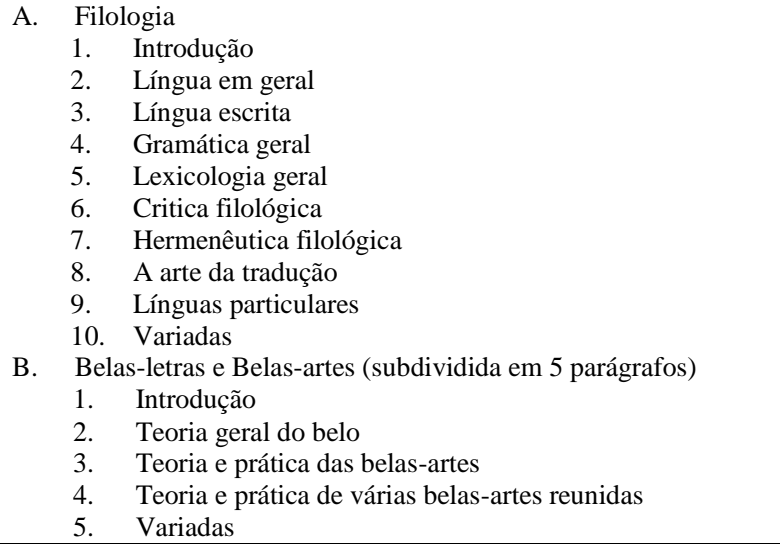 \\
\hline $\begin{array}{l}\text { CIÊNCIAS HISTÓRICAS } \\
\text { (terceira classe) }\end{array}$ & $\begin{array}{ll}\text { 1. } & \text { Introdução } \\
\text { 2. } & \text { Ciências históricas descritivas } \\
\text { 3. } & \text { Ciências históricas narrativas } \\
\text { 4. } & \text { Ciências históricas auxiliares }\end{array}$ \\
\hline $\begin{array}{l}\text { CIÊNCIAS FILOSÓFICAS } \\
\text { (quarta classe) }\end{array}$ & $\begin{array}{ll}\text { A. Ciências filosóficas teóricas } \\
\text { 1. Introdução } \\
\text { 2. Ciências antropológicas } \\
\text { 3. Ciências filosóficas teóricas propriamente ditas } \\
\text { B. Ciências morais e politicas } \\
\text { a. Ciência moral ou filosófica prática } \\
\text { 1. Introdução } \\
\text { 2. Ciências filosóficas práticas } \\
\text { b. Ciência Política } \\
\text { 1. Introdução } \\
\text { 2. Política teórica universal } \\
\text { 3. Política prática universal } \\
\text { 4. Política teórica e prática aplicada às necessidades dos } \\
\\
\text { 5. estados particulares } \\
\text { C. Viênadas } \\
\text { 1. Introdução } \\
\text { 2. Ciências filosóficas metódicas } \\
\text { 3. Variadas }\end{array}$ \\
\hline $\begin{array}{l}\text { CIÊNCIAS MATEMÁTICAS E FÍSICAS } \\
\text { (quinta classe) }\end{array}$ & $\begin{array}{l}\text { A. Ciências Matemáticas } \\
\text { a. Introdução } \\
\text { b. Matemática pura } \\
\text { 1. Matemática pura elementar } \\
\text { 2. Matemática pura transcendental } \\
\text { c. Matemática aplicada } \\
\text { 1. Âs ciências históricas e politicas } \\
\text { 2. Às ciências físicas } \\
\text { 3. Às artes e ao trabalho } \\
\text { d. Variadas } \\
\text { B. Ciências Físicas } \\
\text { a. Fisiografia ou história natural } \\
\text { 1. Introdução } \\
\text { 2. História natural }\end{array}$ \\
\hline
\end{tabular}




\begin{tabular}{|c|c|}
\hline & $\begin{array}{ll}\text { b. } & \text { Variadas } \\
\text { 1. } & \text { Ińsica } \\
\text { 2. } & \text { Física geral } \\
\text { 3. } & \text { Física matemática } \\
\text { 4. } & \text { Física experimental } \\
\text { 5. } & \text { Variadas } \\
\text { c. } & \text { Química } \\
\text { 1. } & \text { Introdução } \\
\text { 2. } & \text { Química teórica } \\
\text { 3. } & \text { Química prática } \\
\text { 4. } & \text { Variadas } \\
\end{array}$ \\
\hline $\begin{array}{l}\text { CIÊNCIAS ECONÔMICAS E MÉDICAS } \\
\text { (sexta classe) }\end{array}$ & \begin{tabular}{ll} 
A. & \multicolumn{2}{c}{ Ciências econômicas } \\
1. & Introdução \\
2. Economia rural \\
3. & Economia florestal \\
4. & Economia doméstica \\
5. & Variadas \\
B. & Ciências médicas \\
1. & Introdução \\
2. & Ciências médicas teóricas \\
3. Ciências médicas práticas \\
4. Variadas \\
5.
\end{tabular} \\
\hline $\begin{array}{l}\text { ARTES E OFÍCIOS } \\
\text { (sétima classe) }\end{array}$ & $\begin{array}{ll}\text { 1. } & \text { Introdução } \\
\text { 2. } & \text { Cultura e exploração de produtos naturais } \\
\text { 3. } & \text { Manufaturas e fábricas } \\
\text { 4. } & \text { Artes e trabalhos mecânicos } \\
\text { 5. } & \text { Comércio } \\
\text { 6. } & \text { Artes ginásticas } \\
\text { 7. } & \text { Artes militares } \\
\text { 8. } & \text { Artes de diversão e lazer } \\
\text { 9. } & \text { Artes supersticiosas } \\
\end{array}$ \\
\hline $\begin{array}{l}\text { CIÊNCIAS POSITIVAS } \\
\text { (oitava classe) }\end{array}$ & $\begin{array}{ll}\text { A. } & \text { Jurisprudência } \\
1 . & \text { Introdução } \\
2 . & \text { Ciências jurídicas teóricas } \\
3 . & \text { Ciências jurídicas práticas } \\
4 . & \text { Variadas } \\
5 . \quad \text { Direito internacional } \\
\text { B. Teologia } \\
\text { 1. } \quad \text { Introdução } \\
2 . \quad \text { Tipos de religião e de teólogos positivos } \\
\text { 3. Partes da ciência teológica } \\
\text { 4. } \quad \text { Variadas } \\
\end{array}$ \\
\hline $\begin{array}{l}\text { MISTURAS, COLEÇÕES, POLÍGRAFOS } \\
\text { (nona classe) }\end{array}$ & Variadas, coleções e polígrafos \\
\hline $\begin{array}{c}\text { MANUSCRITOS, CURIOSIDADES LITERÁRIAS, } \\
\text { MONUMENTOS, TIPOGRAFIAS } \\
\text { (décima classe) }\end{array}$ & Manuscritos, curiosidades literárias, monumentos e tipografias \\
\hline
\end{tabular}

\section{Quadro 2 - Representação do Système du citoyen Butenschoen}

Fonte: Peignot (1802b, p. 214-21)

Outro sistema que se apresenta como um dos mais debatidos e mencionados ao longo dos dois volumes do DRB, o sistema bibliográfico de Girard divide o conhecimento humano em 6 classes, incluindo a divisão a "tecnologia" como conjunto de saberes do mundo sensível, porém distante ainda do uso de termo pós-século XVIII.

\begin{tabular}{|c|l|}
\hline $\begin{array}{c}\text { Classes/Categorias } \\
\text { principais }\end{array}$ & \multicolumn{1}{c|}{ A que se refere } \\
\hline $\begin{array}{c}\text { TEOLOGIA } \\
\text { (primeira classe) }\end{array}$ & Se refere aos textos, comentários, dogmáticas, pregadores, místicos e liturgias. \\
\hline $\begin{array}{c}\text { NOMOLOGIA } \\
\text { (segunda classe) }\end{array}$ & $\begin{array}{l}\text { Tudo o que diz respeito à sociedade da qual ela é indispensavelmente vinculada, ao cumprimento e conservação } \\
\text { das leis. Reúne disciplinas como: o direito civil, corporologie (estudo das sociedades particulares, ex: religiosa, } \\
\text { civil), l'éthicologie (o estudo da ética), o thésmologie (o estudo dos livros de modos, costumes, tradições, ritos e } \\
\text { cerimônias) e praxéonomie (estudo das sociedades particulares e temporárias, ex. famílias). }\end{array}$ \\
\hline $\begin{array}{c}\text { HISTORIOGRAFIA } \\
\text { (terceira classe) }\end{array}$ & $\begin{array}{l}\text { Que reúne registros, histórias, personologie (história de pessoas particulares), littérologie (fatos e eventos } \\
\text { literários), ficções e coleções. }\end{array}$ \\
\hline FILOSOFIA & Se subdivide em matemática, cosmografia, physiographie (os meios para conhecer as produções da natureza), \\
\hline
\end{tabular}




\begin{tabular}{|c|l|}
\hline (quarta classe) & física, medicina e spiritologie (natureza e essência do espirito, metafísica e lógica). \\
\hline $\begin{array}{c}\text { FILOLOGIA } \\
\text { (quinta classe) }\end{array}$ & A que pertencem: lexicologia, eloquência, poesia, teatro, literatura e crítica. \\
\hline $\begin{array}{c}\text { TECNOLOGIA } \\
\text { (sexta classe) }\end{array}$ & $\begin{array}{l}\text { Engloba as artes cívicas, acadêmicas, ginásticas, visuais, ligadas à nutrição e as mystériques (misticismos, cultos } \\
\text { pagãos e outros) }\end{array}$ \\
\hline
\end{tabular}

Quadro 3 - Representação do Système bibliographique de l'abbé Girard Fonte: Peignot (1802a, 1802b)

Por sua vez, o Système de Laire dialoga com outros sistemas já existentes, demarcando as trocas e influências no desenvolvimento de tais artefatos conceituais, como o caso da menção à Girard. Do mesmo modo, verifica-se a influência direta de Bacon e seu Novo Organon. A partir de cinco grandes divisões, Laire concebe a organização das ciências entre razão, imaginação, memória, necessidades físicas e necessidades morais.

1. La raisón a crée les ouvrages relatifs à la pluitosophie.

2.0 L'imagination a donné le jour à la poésie et aux arts d'agrément.

3.o La mémoiro a produit l'histoire.

$40^{\circ}$ Les besoins physiques ont donné lieu aux arts et métiers et à l'agriculture.

5. Et les besoins moraux à l'art de la parole et à tout ce qui tient aux lois de l'ordre social. Il appelle cette dernière classe nomologie, mot emprunté de l'abbé Girard.

Tel est le. plan sommaire du systeme de classification présenté pạr Laire. On trouvera les détails dans les mąnuscrits qui sont entre les mains du citoyen Coste, Besançon.

Figura 6. Fragmento inicial do verbete Système du citoyen Butenschoen em Gabriel Peignot

Fonte: Peignot (1802b)

A breve síntese aleatória dos sistemas reunidos por Peignot (1802b) demonstra a potencialidade de compreensão sócio histórica da Modernidade e da epistemologia a partir dos chamados "sistemas bibliográficos". O panorama quantitativo sugere a amplitude mínima (se pensado o conjunto de sistemas potenciais não arrolados pelo DRB) já considerável de multiplicidade de tentativas de classificar o conhecimento, a partir da correlação empírica com as obras ali existentes e as propostas teóricas nela contidas.

Ainda sob o ponto de vista quantitativo, algumas variáveis surgem como elementares para identificação da relevância do levantamento peignotiano. Mesmo com a ausência inicial de alguns dados aqui e acolá nas descrições dos sistemas, a temporalidade (idade dos sistemas), a 
tipicidade (das ciências), a autoridade (classificacionistas), a exaustividade (extensão das divisões científicas), a contiguidade (relação entre as ciências), a sistemática (o método classificatório) e a esquemática (visualização dos dados) são elementos que convidam à possibilidade de estudos aprofundados sobre a relação entre Modernidade, ciência e classificação, a partir do século XVII, foco central dos levantamentos de Peignot (1802b). Depreende-se das primeiras impressões, no plano qualitativo, a manifesta "passagem" das ciências do plano metafísico para o físico. Distinguindo-se dos arranjos medievais, as ciências morais e mecânicas começam a figurar como "parte do todo", movimento esse que pós-século XVIII ganhará a reconfiguração final tais "empiricidades" ganham a condição de centralidade.

A fronteira entre os "velhos sistemas", condenados por Bacon e Condillac, que dividiam os saberes a partir da máxima especulação, e os "novos sistemas", objetivamente dedicados ao plano das ciências empíricas, aparece na "coleção sistêmica" de Peignot. O confronto entre os sistemas de Ameilhon, Baillet e Montanus pode demonstrar essa "guerra classificatória". A luta, pois, pela emancipação de conceitos disciplinares está exposta: de um lado, antigas macro-noções e sua posição nos sistemas começam a ser substituídas ou realocadas, como o caso do "tradicional" sistema de Ameilhon e sua reconfiguração da Teologia - talvez um dos mais sintomáticos movimentos do século XVII refletidos nos sistemas bibliográficos. Os "primeiros passos" das ciências sociais "propriamente ditas" também podem ser visualizados: em Girard a Nomologia abarcará do direito ao estudo das práticas historicizadas, ou seja, a "praxionomia" atentar-se-á para a investigação das sociedades particulares e temporárias, como as famílias.

Os conceitos teoréticos também podem ser visualizados em sua luta por emancipação sob os efeitos do empirismo. As ramificações da "História" no sistema da Biblioteca Nacional de Paris sugerem esse embate e a demarcação de fronteiras, fundamentando-se em uma "recente" geografia política moderna, isolando as condicionantes espaço-temporais, de por exemplo, Inglaterra, Escócia e Irlanda, Portugal e Espanha. Do mesmo modo, os conceitos-ferramentais, como a eloquência e a crítica, espécie de conceito e método, se reconfiguram como categorias ora analíticas, ora sintéticas. Tais manifestações são objetivas no sistema de Butenschoen, nos destaques, por exemplo, para as ciências históricas e as artes e ofícios (parte também das centralidades dos verbetes no sistema da Enciclopédia).

Eis, pois, uma economia política da epistemologia em sua dinâmica de lutas: os enunciados que demarcam macro-conceitos evidenciam a disputa entre o discurso sobre as ciências, as ciências do discurso e as ciências proprietárias do discurso. A epistemologia da Física, por exemplo, nas descrições peignotianas, sintetiza esse jogo de forças e, pela via da empiria, do trato com o mundo físico, determina o avanço para a fundamentação da ciência proprietária dos grandes enunciados de uma "nova instauração" dos saberes. Os sistemas bibliográficos nos narram tal 
guerra a partir de cada conceito enunciado, de cada divisão demarcatória das disposições entre tais conceitos. Como nos lembra Bourdieu (2004, p. 139-140),

Os esquemas práticos do ritual são realmente schemata tou sômatos, esquemas geradores de movimentos fundamentais, como ir para cima ou para baixo, erguer-se ou deitar-se, etc. E é apenas sob o olhar do observador que o ritual passa de dança à álgebra, de ginástica simbólica a cálculo lógico.

Poderíamos dizer, a partir do conjunto de esquemas sistemáticos e seus arranjos reunido por Peignot (1802b), que do cálculo lógico passamos à guerra da economia política da epistemologia, à disputa pela afirmação do enunciado autorizado a se tornar a "entrada" por onde todos os demais devem "passar", antes de se "tornarem" ou de se "afirmarem" ciências. E nesse movimento de "ir para cima" e-ou de "ir para baixo" de um e outro conceito no arranjo sistêmico, a "positividade" de uma verdade sobre o empírico ganha configurações conforme o tempo-espaço de sua enunciação. O caso da Física, a antiga Filosofia (especulativa) da Natureza, fica claro no sistema de Butenschoen: a quinta classe (Ciências Matemáticas e Físicas), demonstra a estrutura de um modelo epistêmico que se consolidará como prioritário no discurso de legitimação científica a partir do Iluminismo, mesmo quando tratamos da emancipação das chamadas ciências humanas e sociais. E tal condição está ali expressa, entre os conceitos teoréticos e os conceitos-ferramentas, como "Matemática aplicada às artes e ao trabalho" e "Matemática aplicada às ciências históricas e políticas", próximas, por sua vez, de uma "Física experimental" e da própria "Física matemática", "revelação" de encontros disciplinares fundamentais para o avanço das ciências exatas e para a influência sobre as ciências humanas.

Por fim, podemos perceber, do plano macro de compreensão dos sistemas bibliográficos manifestados em Peignot (1802b) ao plano micro, as relações entre as coisas-artefato e os artefatos conceituais. Eis a "transcondição" de toda a sistemática dos repertórios bibliográficos: tais conceitos, tais instrumentos, ora "plenamente" analíticos, ora "plenamente" funcionais, demonstram sua condição de "coisa", materialidade da língua fixada no espaço-tempo; são tais sistemas, ao mesmo tempo, artefatos conceituais que permitem uma compreensão metalinguística de uma realidade epistêmica, manifestando a possibilidade de reconhecer tal ente, tal condição de existência desse ou daquele saber. Ao revelar uma "linguagem primitiva" da ciência moderna, os sistemas bibliográficos reunidos na obra peignotiana permitem a fundamentação de uma cartografia da ciência, assim como de suas formas de constituição, de luta pelo próprio desenvolvimento em seu contexto de (re)definição. 


\section{Considerações finais: a metabibliografia científica dos sistemas em Peignot}

O homem é agente e intérprete da natureza; ele faz e entende somente aquilo que observa da ordem da natureza na prática ou por inferência; ele não sabe e não pode fazer mais. (BACON, 2014 [1620), p 47].

Como reflexões conclusivas, apontamos para o potencial de discussões sociocríticas sobre "metabibliografia científica" revelada pelos "sistemas peignotianos", fonte central para a história da ciência e para o desenvolvimento de uma cartografia epistemológica, a partir do potencial da classificação bibliográfica. Faz-se necessário destacar a ausência da uma reflexão profunda sobre a construção do método de Conrad Gesner, mencionado de maneira superficial no DRB. Peignot (1802a, b) não procura distinguir, nem desenvolver o debate sobre a obra gesneriana e seu método.

No entanto, se a exaustividade ausente, bem como a inexistência de um padrão de descrição para os exemplos do verbete "sistemas bibliográficos", resulta na dificuldade da investigação direta sobre os dados de Peignot (1802a, b), isso não inviabiliza a compreensão potencial do conjunto de inferências passíveis de ser identificadas segundo os arranjos reunidos pelo trabalho metabibliográfico peignotiano. Peignot $(1802 a, b)$ nos oferece um território empírico pouco explorado para um "garimpo conceitual": a coleta de conceitos e de manifestações que repercutem diretamente em uma janela para compreensão da ciência, da ciência das classificações e da classificação como modo de tecer, revelar e desenvolver a ciência, como a linguagem em Condillac (1991) apontava.

A problemática dos sistemas apresentadas por Peignot (1802a, b) permite ainda o reconhecimento de fontes para a história da ciência e para uma cartografia epistemológica distinta para uma historiografia das classificações. Outro olhar sob os "sistemas peignotianos" representa a possibilidade de compreender as dinâmicas das vertentes epistemológicas e suas institucionalizações. Por fim, reafirmamos a possibilidade de compreensão da fundamentação de uma "metabibliografia científica", ou seja, a capacidade de revelar saberes a partir de uma preocupação em repertoriar e posicionar cada sistema existente.

$\mathrm{Na}$ visão conceitual da Enciclopédia, ciência e arte podem fazer sistemas. Porém, a ciência se propõe dar razão aos fatos. A arte nos prepara para conhecê-los e os traz à luz. De um lado, a Física seria uma ciência modelo para essa racionalidade; a Política, uma ciência modelo desse modo de demonstração. Por sua vez, ciências como Química e Medicina atuariam em ambas as ambiências: dar razão e preparardemonstrar. (DIDEROT, D'ALEMBERT, 2015, [1751]).

Acreditamos que o pensamento bibliográfico atua nessas e outras dimensões, constituindo um modo de ser que antecipa, acompanha e ultrapassa razão e demonstração no plano epistêmico, como teoria, 
método e ferramenta de visualização da árvore do conhecimento. Os sistemas cartografados por Peignot demonstram essa metatransconfiguração da Bibliografia e sua sistemática.

\section{Agradecimentos}

A pesquisa que resultou no presente estudo contou com o financiamento do Conselho Nacional de Desenvolvimento Científico e Tecnológico (CNPq) e da Fundação Carlos Chagas Filho de Amparo à Pesquisa do Estado do Rio de Janeiro (FAPERJ).

\section{Referências}

BACON, F. Novo órganon. São Paulo: Edipro, 2014.

BOURDIEU, P. Coisas ditas. São Paulo: Brasiliense, 2004.

CARVALHO, R. S. Lavoisier e a sistematização da nomenclatura química. Scientiæ Zudia, São Paulo, v. 10, n. 4, p. 759-71, 2012.

CONDILLAC, E. B. Traité des systèmes (1749). Fayard: Paris, 1991.

COUZINET, V. Fabrique de la liste: un dipositif entre mémoire et commémoration. In: Journée scientifique internationale du Réseau Mussi. Rio de Janeiro: Rede Mussi, 2012. p. 132-152.

- Des pratiques érudites à la recherche: bibliographie, bibliologie. In: Approche de l'information-documentation: concepts fondateurs. Toulouse: Cépaduès-Éditions, 2011. p. 167-186.

. Complexidade e documento: a hibridação das mediações nas áreas em ruptura, RECIIS - R. Eletr. de Com. Inf. Inov. Saúde. Rio de Janeiro, 2009/3a, (Vol. 3), p. 10-16.

. Transmitir, difundir: formas de institucionalização de uma disciplina, Perspectivas em Ciência da Informação, 2009/14b, (Número especial), p. 5-18.

Réprésenter, répertorier, transmetre: formes d'institutionnalisation d'une discipline. In.: Colloque Médiations et Usages des Savoirs et de I'Information: un dialogue France - Brésil. Rio de Janeiro: UFRJ, 2008. p. 63-81.

Le document: leçon d'histoire, leçon de méthode, Communication et langages, n. 140, 2004a. p. 19-29.

DIDEROT, D.; D'ALEMBERT, J. L. R.. Enciclopédia, ou Dicionário razoado das ciências, das artes e dos ofícios. São Paulo. Editora Unesp, 2015.

FOUCAULT, M. A Arqueologia do saber. 7. ed. Rio de Janeiro: Forense Universitária, 2010. 
OTLET, P. Traité de documentation: le livre sur le livre: théorie et pratique. Bruxelas: Editiones Mundaneum, 1934.

SALDANHA, G. S. Modernidade: uma impressão. InCID: Revista de Ciência da Informação e Documentação, v. 7, p. 7-22, 2016

A posição da Bibliografia na epistemologia de Peignot no Setecentos. Informação \& Informação (UEL. Online), v. 20, p. 118-142, 2015.

- O esquema e as formas simbólicas: uma 'arqueologia filosófica' do esquema no pensamento bibliológico. Tempo Brasileiro, v. 203, p. 79-102, 2015.

PEIGNOT, G. Dictionnaire raisonné de bibliologie, tomo I. Paris: Chez Villier, $1802 a$. tomo II. Paris: Chez Villier, 1802b.

WITTGENSTEIN, L.O livro azul. Lisboa: Ed.70, 1992a.

Investigações Filosóficas. 2. ed. São Paulo: Abril Cultural, 1979. 